\title{
Impact of Lockdown in the FMCG sector of the Indian Stock Market - Analysis using Statistical Methods
}

\author{
M. Vivek Prabu ${ }^{1}$, R. Karthika ${ }^{2}$ \\ 1. Assistant Professor of Mathematics, ${ }^{2}$. M.Sc., Mathematics, \\ Kongunadu Arts and Science College (Autonomous), Coimbatore - 641 029. India
}

Article History:Received:11 January 2021; Accepted: 27 February 2021; Published online: 5 April 2021
Abstract: The Covid19 outbreak has shattered the Global economy and Indian economy too had got no
exemption from it. Despite the GDP of India moving in the negative trend, very few sectors like Pharmaceutical
and FMCG have shown some positive signs because of this pandemic and the lockdown followed by it.
Consumer staples will always remain essential irrespective of the economical movement. In particular, during
the tougher times, whenever there arises an unprecedented scenario, the humankind will always try to safeguard
itself and in turn that will certainly cause a high demand in the FMCG sector. In this paper, we will be analysing
the impact of lockdown in the movement of the FMCG sector using some of the Statistical tools. Keywords: GDP, NSE, Nifty 50, FMCG Sector, Stock Analysis, Covid19, Lockdown, Pandemic, Statistical Methods

\section{Introduction}

A Stock exchange otherwise called as the Securities exchange refers to an exchange in which the shares of stocks of the listed companies are bought and sold by the traders and investors. There are two stock exchanges in India, namely the National Stock Exchange (NSE) and the Bombay Stock Exchange (BSE). Thousands of companies are listed under these exchanges and each of which is placed under a specified sector. There are around 11 stock sectors, the movement of which are highly responsible for the economic status of any country. The Fast Moving Consumer Goods (FMCG) or the Consumer Packaged Goods (CPG) is one among those sectors which currently holds the $4^{\text {th }}$ place in the Indian Economy.

The FMCG industry takes the role of producing, distributing and marketing the consumer goods that are in the rapid consumption on a daily basis. The unprecedented scenario in our day-to-day life in turn leaves a huge impact over the growth/decline of this sector. The Covid-19 invasion in India has also affected the economical standing of the FMCG sector in a larger extent. Thus, in this paper, we intend to statistically analyse the impact of the pandemic and the lockdown forced by it, on the movement of the FMCG sector. We further make a comparative study between the NSE index, NIFTY-FMCG index and in particular, the close prices of the stocks of the Britannia Industries, which serves as one of the leading front-liners in this sector.

\section{Preliminaries}

In this section, we shall mention the basic terminologies which are commonly used in the analysis of stock market.

\subsection{Stock Market}

The Stock Market is a central and a broader marketing platform wherein the buying and selling of the shares issued by the public listed companies take place on a regular basis.

\subsection{Stock}

A Stock generally refers to a kind of security that represents the ownership of a particular company or a corporation that may be issued in the marketplace. It is also known as Equity.

\subsection{Share}

The Shares are simply the units of a stock which are fluctuating in nature, depending on the market value of the stock.

\subsection{Share Holder}

A Share Holder or a Stock Holder is an individual or an institution who/which owns one or more shares of a public or a private company.

\subsection{Dividend}


A Dividend is a share of profits or rewards that a company pays to its shareholders. It is merely decided by the company's board of directors and it may be issued in the form of cash, stock or payment. The company's net profit is the source of dividends.

\subsection{National Stock Exchange (NSE)}

National Stock Exchange of India Limited which is located in Mumbai, was established in the year 1992 as the first electronic exchange in India. It is now the leading stock exchange of the country, offering trade and investment in the equity, derivatives and the debt markets.

\subsection{National Index Fifty 50 (NIFTY 50)}

NIFTY is the blend word of 'National' and 'Fifty', meaning that it consists of 50 active stocks and it is the equity benchmark index of the NSE.

\subsection{Bombay Stock Exchange (BSE)}

Bombay Stock Exchange was established in the year 1875 in Mumbai and it is the Asia's first stock exchange. It provides the fastest stock exchange in the world and it offers trade in equity, currencies, debts, derivatives and mutual funds.

\subsection{Sensex}

Sensex or the Sensitive Index is the stock-market index of the top 30 active trading stocks of the companies listed on the Bombay Stock Exchange.

\subsection{Open Price:}

The price at which the market opens for trading on a market day is said to be the open price.

\subsection{Close Price:}

The Last Traded Price (LTP) during the closing time of the market is known as the close price of the day.

\subsection{Simple Moving Average (SMA) ${ }^{[1]}$}

Simple Moving Average (SMA) is formed by computing the average price of a security over a specific number of periods. Most moving averages are based on the closing prices. SMA provides resistance and support. It indicates signals to sell or buy and it make easier to view the price trend of a security.

$$
\text { SMA }=\frac{\sum N}{n}
$$

where $\sum N=$ Period sum, $\mathrm{n}=$ number of days.

\subsection{Exponential Moving Average (EMA) ${ }^{[1]}$}

An Exponential Moving Average is similar to SMA. EMA evaluates the trend direction over a period of time. EMA is the best indicator for investors who deal with intraday and fast moving markets. EMA gives a higher weight to recent prices, while SMA assigns equal weight to all values. EMA can be calculated for 12 days, 26 days and so on.

$$
\text { EMA }=(C-\text { YEMA }) * \text { W.M. + YEMA }
$$

where

C - Closing Price,

YEMA - Yesterday's EMA,

W.M. - Weight Multiplier $=\frac{2}{(n+1)}$

\subsection{Moving Average Convergence Divergence (MACD) ${ }^{[1]}$}

The Moving Average Convergence Divergence [MACD] is an indicator in Technical analysis used to identify a new trend such as a bullish (or) bearish flux. MACD is all about convergence and divergence of the two moving averages.

$$
\text { MACD = (12 day EMA - } 26 \text { day EMA })
$$

Positive MACD indicates that the 12 day EMA is above the 26 day EMA. Here shorter EMA diverges from the longer EMA. This means upside momentum is increasing. 
Negative MACD indicates that the 12 day EMA is below the 26 day EMA. Here shorter EMA diverges below the longer EMA. This means downside momentum is increasing.

\subsection{Relative Strength Index (RSI) ${ }^{[1]}$}

The Relative Strength Index (RSI) is a momentum oscillator that measures the speed and change of price movements. It oscillates between 0 and 100 .

$$
\begin{gathered}
\text { RSI }=100-\frac{100}{(1+R S)} \\
\text { Relative Strength }(\mathrm{RS})=\frac{\text { Average gain }}{\text { Average loss }}
\end{gathered}
$$

RSI is used to identify oversold and overbought price areas.

If RSI is above 50, then it is considered as bullish behaviour and if its value is below 50, then it is considered as bearish in nature.

\section{TECHNICAL ANALYSIS}

Technical analysis comprises the methods of examining the investments and the price movements in the market and thereby predicting the direction of the prices. We perform the analysis with the help of patterns and signals over a particular period, assessed from the analytical chart tools. The usage of market indicators provide us with the probability of an asset's direction and continuation.

In this section, we will be considering the historical data of the FMCG sector for the previous and the current financial years. In particular, we will be more interested to analyse the movement of the stocks of the Britannia Industries Limited.The NSE index will serve as the benchmark for this study. This analysis will help us to understand the unwavering movement of the FMCG sector due to the impact of lockdown forced by the Covid-19 pandemic. We will be using statistical tools like Frequency analysis, Simple Moving Average (SMA), Exponential Moving Average (EMA) for this purpose.

\subsection{Graphical Representation and Interpretation}

The data between 01.04.2019 and 10.12.2020 of the NSE index, NIFTY index - FMCG and the Britannia Industries Limited in particular have been collected and using them, we have calculated MACD, RSI and PL\% which are nothing but the technical indicators which supports us to predict the futuristic trend of this sector. The following are the graphical representation of these indicators which are acquired from our technical analysis.

\subsubsection{SMA}

The Simple Moving Average of the NIFTY-FMCG, NSE index and the Britannia Industries Limited are depicted below.

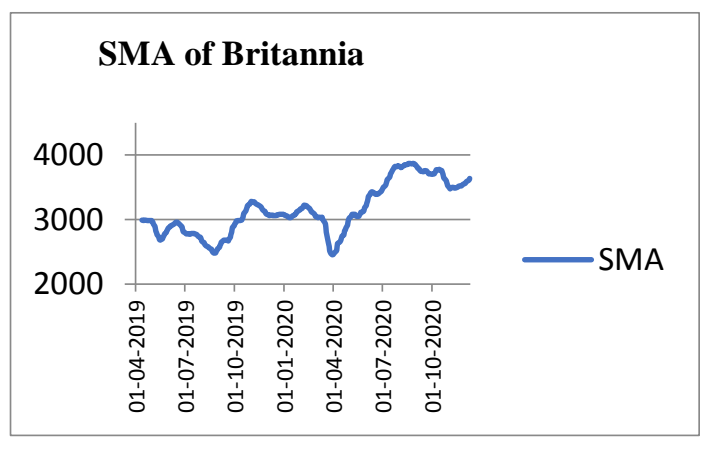

SMA of NSE

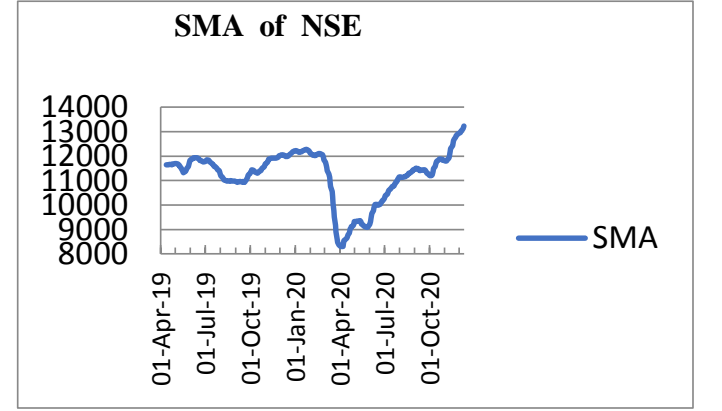

\subsection{2.} EMA

The

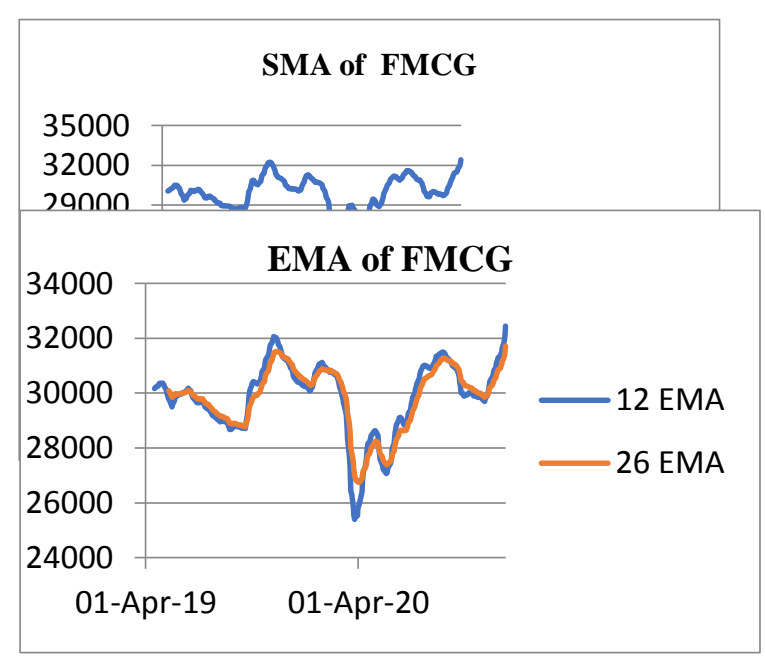


Exponential Moving Average of the NIFTY-FMCG, NSE index and the Britannia Industries Limited are depicted below.

$$
\text { EMA }=(\mathrm{C}-\text { YEMA }) * \text { W.M. }+ \text { YEMA }
$$
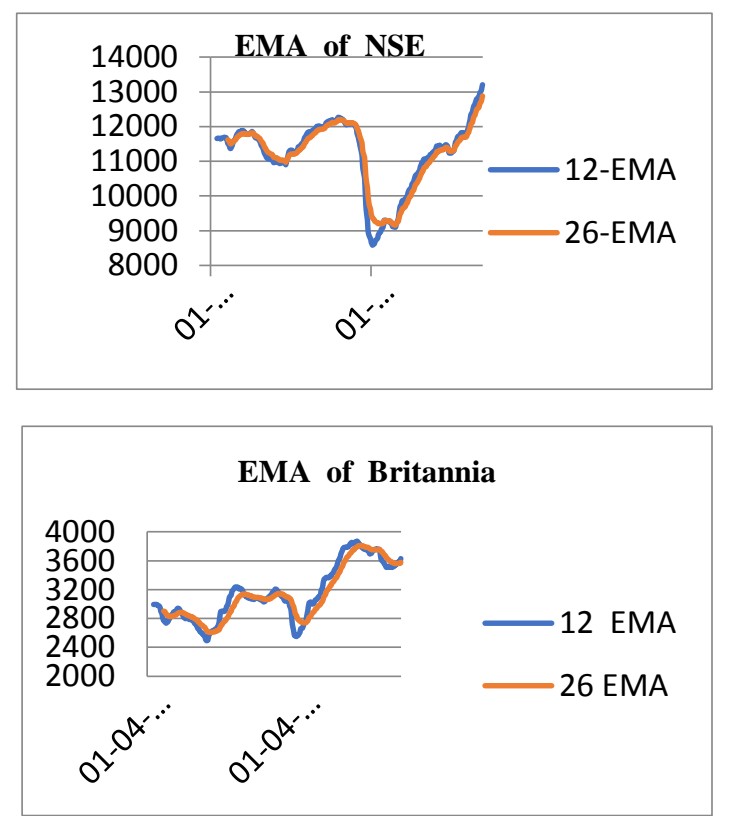

\subsubsection{MACD}

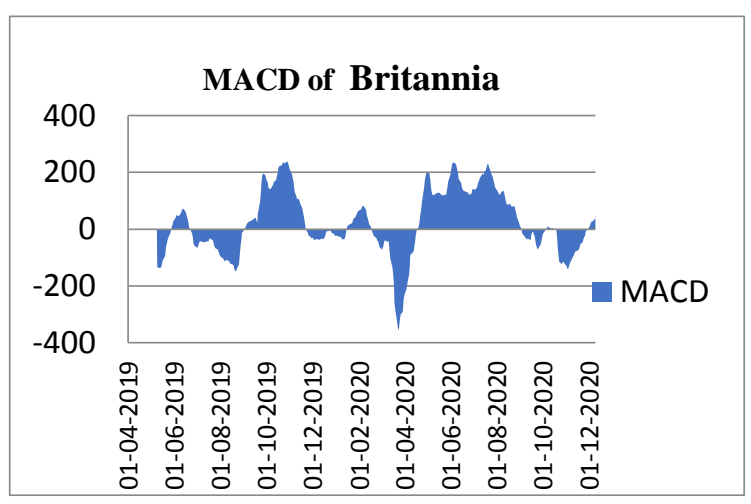

The Moving Average Convergence Divergence of the NIFTY-FMCG, NSE index and the Britannia Industries Limited are depicted below.

$$
\mathrm{MACD}=(12 \text { day EMA }-26 \text { day EMA })
$$

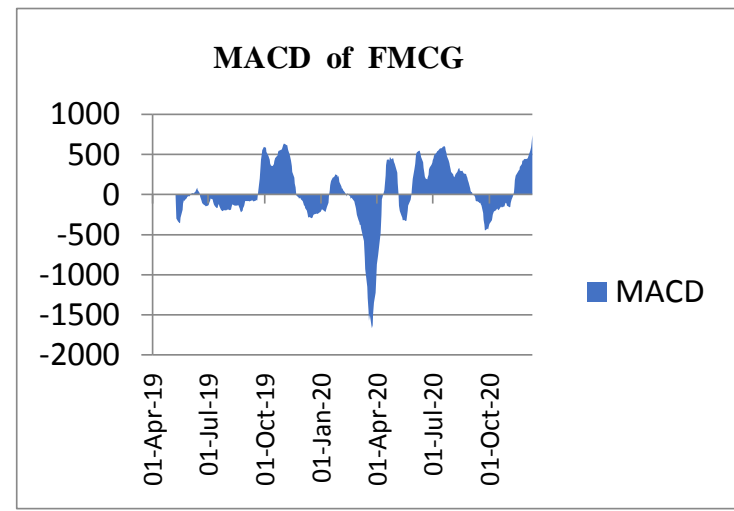

These graphs of MACD for all the three data can be clearly interpreted and we can arrive at a result that the behaviour of the stocks was in a more bearish trend particularly in the month of April 2020. This pattern follows right from the Britannia Industries to the FMCG sector and then to the NSE. The reason for this result could be claimed due to the immediate impact of the imposition of lockdown and thus the market underwent a downward movement.

We also find that the stocks of both the indices and the Britannia Industries were being traded in a bullish trend towards the end of the considered period which is December

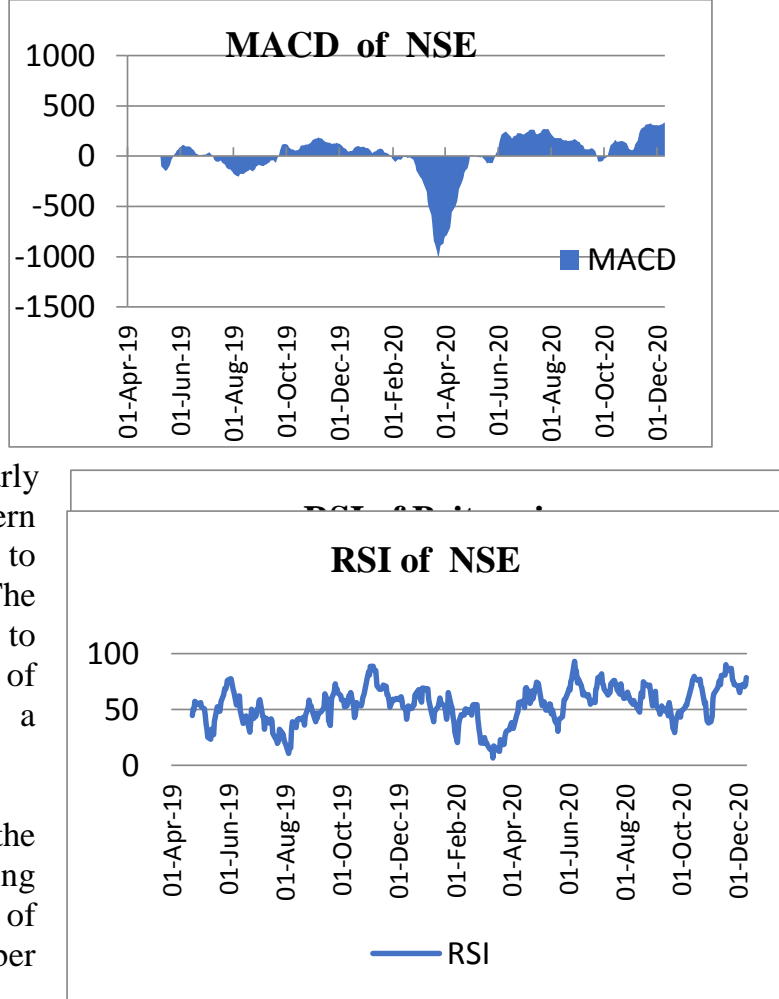


2020.This movement could have happened due to the relaxation of the lockdown as the normal lifestyle was thus setting up slowly.

\subsubsection{RSI}

The Relative Strength Index of the NIFTY-FMCG, NSE index and the Britannia Industries Limited are depicted below.

$$
\text { RSI }=100-\frac{100}{(1+R S)}
$$

The RSI graph generally indicates that the stocks become overbought or oversold depending upon its value.

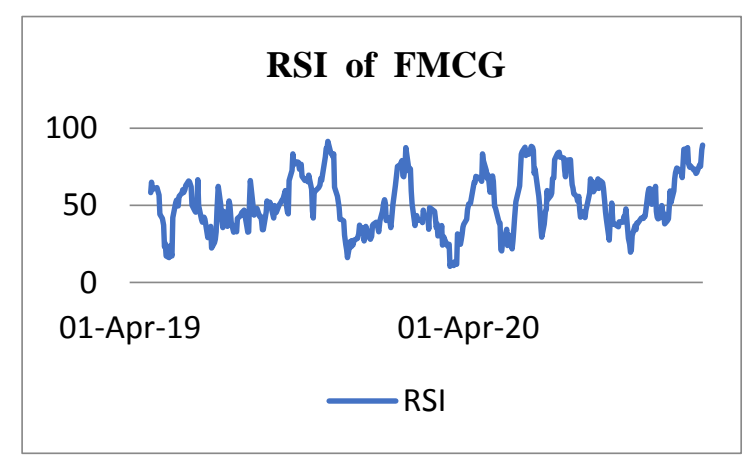

undervalued.
The threeRSI graphs are approximately similar in representation and thus the market conditions of the stocks in all the three fields must also be similar. The graphs are seen fluctuating in both upward and downward movements indicating that the overbought and oversold conditions were not standard.

In a more precise approach, it can be seen that the values of RSI which are greater than 70 are more frequent than the values lesser than 30. Thus the stocks were overvalued comparatively higher than the stocks that were

3.1.5. P\& L \%

The Profit and Loss Percentage of the NIFTY-FMCG, NSE index and the BritanniaIndustries Limited are depicted below.
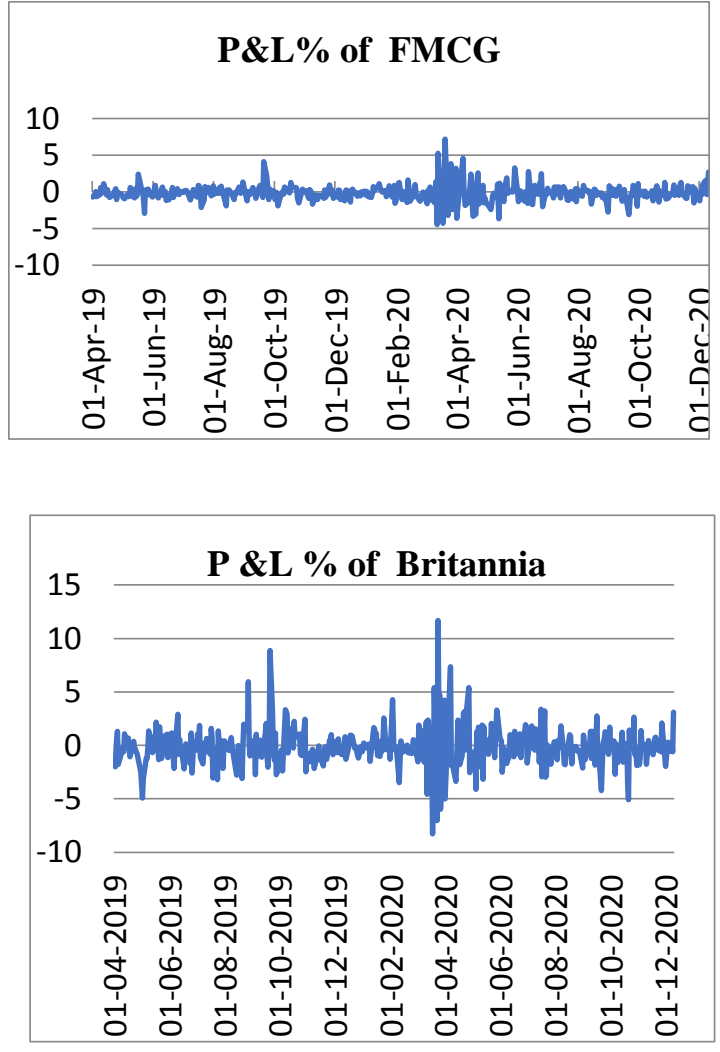

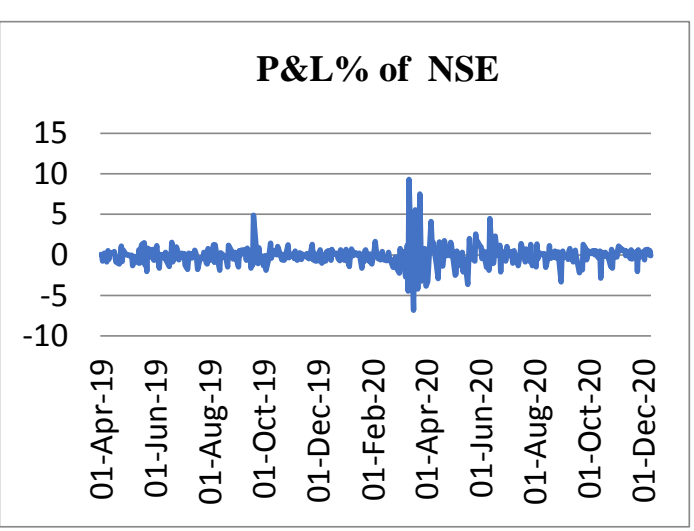

The Profit and Loss percentage graph shows the irregular rising and falling of the lines indicating the subsequent profitability of the respective sector or field. 
This Profit Loss graph can be visualised identically as the gain or loss potentials of all the three fields were identical. It is shown that the profit was considerably high in a particular period of April to May 2020. It is noticeable to see that the FMCG sector along with the contribution of the Britannia Industries Limited has held a good degree of profit percentage in the National Stocks Exchange, despite the impacts of lockdown.

\subsubsection{Frequency Table}

The Frequency Table of the NIFTY-FMCG, NSE index and the Britannia Industries Limited are depicted below. The frequency graph for the consecutive Gain and Loss are drawn for the period of lockdown between 24.03.2020 and 10.12.2020.

The frequency tables and the graph discussed below provide us with a clear understanding about the fluctuating nature of the stock markets even in the period of lockdown. We can see that nearly $30 \%$ of the subsequent trading was in a to and fro movement between Gain and Loss. It is the nature of the market and it will be, irrespective of the other impacts.

The highest gain frequency was found at the rate of 5 consecutive days performed by the Britannia Industries and the NSE around the months of May-June and September-October. The first frequency could be due to the serious impact of lockdown and the second frequency could be due to the relaxations. The frequency of FMCG in these months was seen fluctuating mostly around 1 day and 2 days.

The highest loss frequency streak was marked 9 consecutive days by both the FMCG sector and the Britannia Industries. These frequencies have occurred at the months of April-May and August.

\begin{tabular}{|c|c|c|}
\hline Frequency & Table of & FMCG \\
\hline $\begin{array}{c}\text { No. of } \\
\text { days }\end{array}$ & Gain & Loss \\
\hline 1 & 31 & 20 \\
\hline 2 & 11 & 11 \\
\hline 3 & 2 & 6 \\
\hline 4 & 1 & 2 \\
\hline 5 & & 1 \\
\hline 6 & & 1 \\
\hline \multirow[t]{3}{*}{9} & & 2 \\
\hline & 63 & 97 \\
\hline & Total & 160 \\
\hline
\end{tabular}

\begin{tabular}{|c|c|c|}
\hline Frequency & Table of & Britannia \\
\hline $\begin{array}{c}\text { No. of } \\
\text { days }\end{array}$ & Gain & Loss \\
\hline 1 & 22 & 22 \\
\hline 2 & 14 & 6 \\
\hline 3 & 3 & 6 \\
\hline 4 & 1 & 1 \\
\hline 5 & 1 & 4 \\
\hline 7 & & 1 \\
\hline \multirow[t]{3}{*}{9} & & 1 \\
\hline & 68 & 92 \\
\hline & Total & 160 \\
\hline
\end{tabular}

\begin{tabular}{|c|c|c|}
\hline Frequency & \multicolumn{2}{|c|}{ Table of NSE } \\
\hline $\begin{array}{c}\text { No. of } \\
\text { days }\end{array}$ & Gain & Loss \\
\hline 1 & 23 & 22 \\
\hline 2 & 12 & 12 \\
\hline
\end{tabular}




\begin{tabular}{|c|c|c|}
\hline 3 & 4 & 5 \\
\hline 4 & 1 & 1 \\
\hline 5 & 2 & 2 \\
\hline 6 & & 1 \\
\hline 7 & & 1 \\
\hline & 80 & 80 \\
\hline & Total & 160 \\
\hline
\end{tabular}

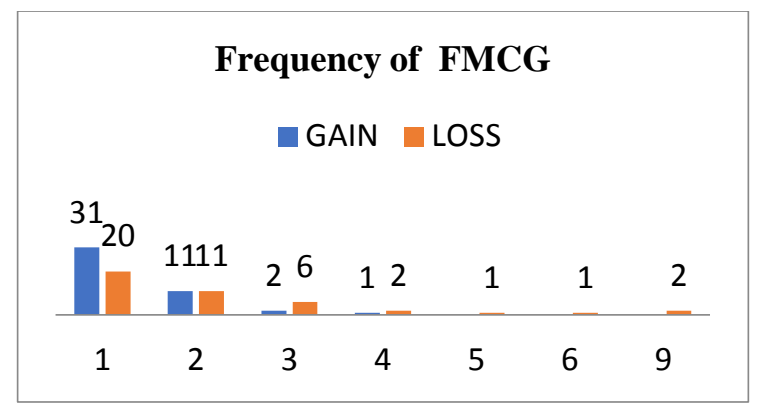

\begin{tabular}{|c|c|c|c|c|c|c|}
\hline \multicolumn{7}{|c|}{ Frequency of FMCG } \\
\hline 2 & 1111 & $2^{6}$ & 12 & 1 & 1 & 2 \\
\hline 1 & 2 & 3 & 4 & 5 & 6 & 9 \\
\hline
\end{tabular}

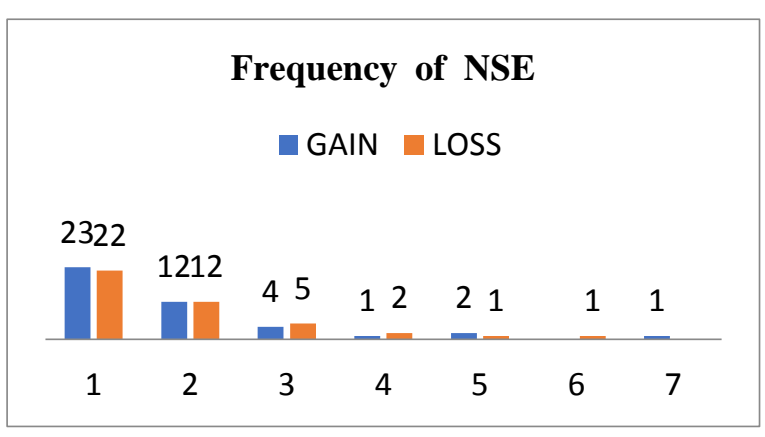

Eventually, this can also be interpreted as the consequence of lockdown and its gradual relaxation. The frequency of NSE in these months was also seen fluctuating around 1 day and 2 days.

\section{Interpretation}

The Covid-19 pandemic is believed to be one of the greatest disasters in the history of mankind, disrupting the business cycle of many countries. In a more unsurprising note, India's economy was affected badly as it was already moving in a prolonged slower rate. The Gross Domestic Product (GDP) growth rate was also at a declining rate which was further expected to go down due to the impact of Covid-19.

This pandemic has shut down the growth of many sectors due to the imposed restrictions. Out of the sectors which were suppressed by this outbreak, the FMCG sector rose out to stand with a more stable performance with a positive sign of improvements. To be noted, this sector was experiencing a slowdown in consumer demand when this pandemic hit 
the world all of a sudden. This lockdown has thus impacted the FMCG sector in a positive manner, as a result of the increased demand for the consumer products.

The analysis shows that the sector was in an oscillatory movement at the initial stages of lockdown, during the month of April and May. While the NSE was performing in a normal way, the FMCG sector and in particular, the Britannia Industries Limited has performed in an appreciative manner. This merely indicates the relatively increased demand for the consumer goods.

According to our analysis, we have arrived the conclusion that the sector was seen growing not only in the initial pandemic period, but also in the subsequent months followed by it. In fact, we see that the FMCG sector experienced a highly significant volume around the month of September and this must be for sure due to the impact of lockdown. Thus, even if the economy goes downward, whenever there arises an unprecedented scenario, the humankind will always try to safeguard itself and in turn that will certainly cause a high demand in the FMCG sector, which is evident from this study.

\section{Reference}

[1]Investment Analysis and Portfolio Management, Prasanna Chandra, Published by Tata McGrawHill Education Private Limited, 2012 (Fourth edition).

[2]M, V. P., S, K., \& M, R. (2020). Research article Fundamental analysis of banking sectors. Kongunadu Research Journal, 7(2), 143-148. https://doi.org/10.26524/krj.2020.34

[3]www.yahoofinance.com and www.moneycontrol.com -Secondary data.

[4]www.nseindia.com- Data of NSE 